\title{
Kar Üzerinde Odun Hammaddesinin Taşınabilir EI Vinci ile Sürütülmesinin Verim Açısından Değerlendirilmesi
}

\author{
Neşe GÜLCI ${ }^{1}{ }^{1}$, Kıvanç YÜKSEL ${ }^{1}$, Abdullah E. AKAY ${ }^{2}$ \\ ${ }^{1}$ Kahramanmaraş Sütçü İmam Üniversitesi, Orman Fakültesi, 46100 Kahramanmaraş/Türkiye \\ ${ }^{2}$ Bursa Teknik Üniversitesi, Orman Fakültesi, 16330 Yıldırım/Bursa/Türkiye \\ *Sorumlu yazar: kyuksel@ksu.edu.tr
}

Geliş Tarihi:30.09.2016

Kabul Tarihi: 13.02 .2017

Özet: Ülkemizde ormanc1lıkta üretim işleri genellikle yaz aylarında gerçekleştirilmekle birlikte odun hammaddesi ihtiyacının artması, iş̧̧i ücretlerinin düşük olması, kış aylarında üretilen odun hammaddelerinin daha kaliteli olması ve kar örtüsü üzerinde çevresel zararlarının az olması gibi olumlu yönleri düşünüldüğünde kış üretimi de yapılabilmektedir. Odun hammaddesi üretim çalışmalarının büyük bir kısmı orman köylüleri tarafindan sınırlı bütçeyle gerçekleştiğinden mekanik üretim araçları (tarım traktörü ve orman traktörü) yeteri kadar kullanılamamaktadır. Bu nedenle dağlık arazide bölmeden çıkarma çalışmaları çoğunlukla insan gücüyle atarak, taşıyarak ve kaydırarak gerçekleştirilmekte olup, bu da özellikle kış aylarında işçileri zorlamakta, zaman ve çevresel kayıplara sebep olmaktadır. Ayrıca üretilen ürünlerde kalite ve kantite kayıpları meydana gelmektedir. Bu çalışmada Kahramanmaraş Orman Bölge Müdürlüğü, Göksun Orman İşletme Şefliği sınırlarında farklı güzergahlarda taşıabilir el vinciyle bölmeden çıkarma çalışmaları verim açısından değerlendirilmiştir. Çalışma kapsamında el vinci ve sentetik halat kullanılarak odun hammaddelerinin kar örtüsü üzerinde yamaç yukarı taşınması sırasında zaman ölçümleri gerçekleştirilmiştir. Ölçümler sonucunda, bütün güzergahlar için ortalama verim değerlerinin $0,99 \mathrm{~m}^{3} / \mathrm{saat}$ ile $2,06 \mathrm{~m}^{3} / \mathrm{saat}$ arasında değiştiği belirlenmiştir. Elde edilen sonuçlara göre, el vinciyle bölmeden çıarma çalışmalarının yüksek hacimli ürünlerde kullanılmasının daha verimli olduğu ortaya konmuştur.

Anahtar Kelimeler: Bölmeden çıkarma, Karlı zeminde sürütme, Taşınabilir el vinci, Zaman Ölçümü

\section{Productivity Assessment of Portable Hand Winch based Skidding Operation on Snow Cover}

Abstract: In Turkey, timber extraction activities are usually carried out in the summer season, yet increased demand on forest products, the low income rates of the loggers, extraction of higher quality products in winter season, and reduced environmental damage on snow cover encourages for timber extraction in winter season. Mechanized harvesting equipment (i.e. agricultural tractors, forestry tractors, etc.) cannot be used sufficiently, since most of the timber extraction activities are carried out by the forestry villagers with a limited budget. Therefore, the logging operations in mountainous areas are usually accomplished by man power as carrying, throwing and sliding the logs, which increases the difficulties of the work and causes high amount of time losses and environmental damages. Besides, this method results in quality and quantity losses of forest products. In this study, the productivity of portable hand winch operation was examined on various skidding trails within the border of Göksun Forest Enterprise Chief in Kahramanmaraş Regional Directorate of Forestry. In the field, the time study measurements were conducted during uphill hauling of timbers on snow cover by using portable hand winch and synthetic rope. The results indicated that productivity of portable hand winch on specified skidding trails ranged from $0.99 \mathrm{~m}^{3} / \mathrm{hr}$ to $2.06 \mathrm{~m}^{3} / \mathrm{hr}$. It was found that volume and quality of log per turn plays important role in productivity of portable hand winch operation.

Keywords: Timber extraction, Skidding on snow cover, Portable hand winch, Time study

\section{Giriş}

Ülkemizde odun hammaddesi üretimi; orman işletmelerine gelir sağlamak ve piyasadaki odun hammaddesi ihtiyacını karşılamak amaciyla idare süresini dolduran dikili haldeki ağaçların kesilerek en yakın orman yoluna ve oradan orman depolarına kadar taşınması aşamalarının tamamını kapsamaktadır (Eroğlu, 2012). Odun hammaddesi üretimi kesme, kabuk soyma, bölümleme, bölmeden çıkarma, yükleme, taşıma, boşaltma ve istifleme ile piyasaya sunma aşamalarından oluşmaktadır (Gülci, 2014). Bölmeden çıkarma çalışmaları, orman ekosisteminin sürekliliği, meşcerede kalan ağaçlar, gençlik ve toprak tahribatı açısından 
önemli bir yere sahiptir (Ünver, 2008; Erdaş ve ark., 2014).

Orman ürünleri transportunda en eski ve ülkemizde en çok kullanılan yöntemlerden birisi doğrudan zemin üzerinde sürütme ile bölmeden çıkarmadır. $\mathrm{Bu}$ yöntem orman toprağına zarar vermekte ve erozyona da sebep olmaktadır. Kar tabakası ile örtülü zemin üzerinde yapılan üretim çalışmaları toprak zararını minimize etmekte ve hasat edilen odunda meydana gelebilecek değer kayıplarını önlemektedir (Tunay ve Çı̆̆, 1994). Odun hammaddesi ihtiyacının giderek artması, işçi ücretlerinin düşük olması, odun hammaddesinin kıș aylarında daha kaliteli olmas1 ve en önemlisi kar örtüsü üzerinde çevreye verilen zararın en aza indirgenmiş olması kış aylarında üretim yapılmasının önemini ortaya çıkarmaktadır (Tunay ve Çığ, 1994).

İnsan ve hayvan gücüyle bölmeden çıarmanın uygun olmadığ 1 alanlarda ve traktörle bölmeden çıkarmanın tercih edilmediği durumlarda, taşınabilir el vinçleri ile kablo çekimi yapılarak bölmeden çıkarma önemli bir alternatiftir (Gülci ve ark.,2014a). Odun hammaddeleri taşınabilir el vinci ile zemin üzerinde sürütülebildiği gibi sürütme konisi ile kombine edilebilmektedir. Sürütme konisi ürünlerin kalan ağaçlara, kütük ve diğer engellere takılma riskini azaltmakta, bu durum verimi artırmakta ve meşcere zararını azaltmaktadır (Akay ve ark., 2014a).

Literatürde taşınabilir el vinciyle bölmeden çıkarma çalışmalarının toprak zemin üzerinde, sürütme konisi ve oluk sistemiyle kombineli olarak uygulaması yer almaktadır (Akay ve ark., 2014a; Akay ve ark., 2014b; Gülci, 2014; Gülci ve ark., 2014b, Gülci ve ark., 2016). Ancak kar üzerinde gerçekleştirilmiş herhangi bir bilimsel çalışma yer almamaktadır. $\mathrm{Bu}$ nedenle bu çalışmada, kar örtüsü üzerinde taşınabilir el vinciyle bölmeden çıkarma çalışmaları zaman ölçümleri yapılarak ve istatistiki temellere dayandırılarak gerçekleştirilmiştir. Elde edilen sonuçlar verim açısından değerlendirilmiştir.

\footnotetext{
Materyal ve Metot

Araştırma alanı

Ormancılıkta kış üretim imkanları doğrultusunda araştırma alanı olarak
}

Kahramanmaraş Orman Bölge Müdürlügüu, Göksun Orman İşletme Müdürlüğü, Göksun Orman İşletme Şefliği 248 no'lu bölme seçilmiştir (Şekil 1). Göksun Orman İşletme Şefliği sınırları 68439.0 ha alanı kapsamaktadır. $\mathrm{Bu}$ alanın yaklaşık \%41,4 (28311.0 ha)'ü ormanlarla kaplıdır. Bu alan coğrafi konum olarak $37^{\circ} 52^{\prime} 40^{\prime \prime}$ - $38^{\circ} 17^{\prime}$ $27^{\prime \prime}$ kuzey enlemleri ile $36^{\circ} 19^{\prime} 36^{\prime \prime}$ - $36^{\circ} 41^{\prime}$ 48 " doğu boylamları arasındadır. Araştırma alanının rakımı ve ortalama eğimi sırasıyla $1509.6 \mathrm{~m}$ ve $\% 22.9$ 'dur.

\section{Kullanılan makine ve ekipmanlar}

Odun hammaddesinin yamaç yukarı sürütülmesinde kullanılan taşınabilir el vinci "PCW5000" marka olup, toplam 100 m mesafeden kablo çekimi yapabilmektedir. Taşınabilir el vinciyle odun hammaddesinin bölmeden çıkarılmasında; sentetik halat (100 m uzunluğunda ve $12 \mathrm{~mm}$ çapında), sürütme konisi (Polimer plastik), zincir çoker (1,5 m), polyester çoker $(2 \mathrm{~m})$, üç adet metal kilit ve iki adet kanca kullanılmıştır.

Uygulamada, taşınabilir el vinci polyester çoker ile dikili halde bulunan ağaca sabitlenmekte, bölmeden çıkarılacak emval ise zincir çoker yardımıyla sentetik halata sabitlenmektedir. Ayrıca, taşınabilir el vinci polyester çoker yardımıyla işçinin omzunda asılı olarak taşınabilmektedir. Sürütme konisi ürünün kalan ağaç, kütük ve köklere takılmasını önleyerek sürütme esnasında meydana gelebilecek zararlardan kalan ağaçları da korumaktadır (Gülci ve ark., 2014b).

Taşınabilir el vinci ile bölmeden çıkarma çalışmaları sırasında zaman ölçümleri için iki adet kronometre kullanılmıştır. Bölmeden çıkarma çalışmalarının gerçekleştiği alandaki ortalama eğimin belirlenmesinde eğimölçer, UTM (Universal Transverse Mercator) koordinatlarının ve rakımın kaydedilmesinde el GPS'den yararlanılmıştır.

Odun hammaddesinin orta çapları çapölçer, boyları ise şerit metre ile ölçülmüştür. Araştırma için gerekli CBS veri tabanının geliştirilmesi ve analizlerin gerçekleştirilmesinde ArcGIS yazılımı, istatistiki analizlerin gerçekleştirilmesinde SPSS yazılımı kullanılmıştır. 


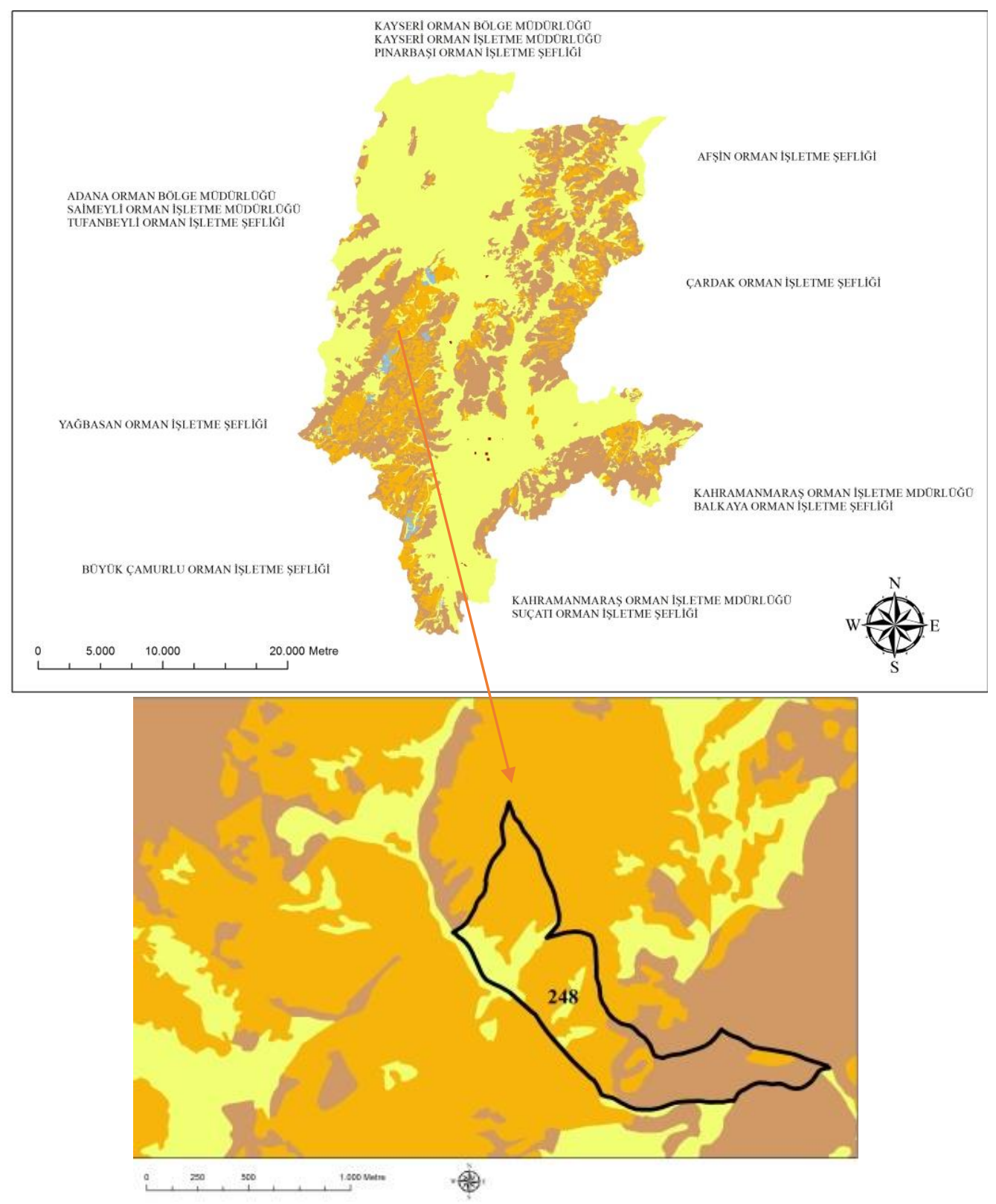

Şekil 1. Araştırma alanı

\section{Arazi uygulaması}

Taşınabilir el vinci ve sürütme konisi kullanılarak gerçekleştirilen bölmeden çıarma çalışması arazide iki farklı eğim grubunda (\%21-33, \%34-50) ve üç farklı güzergah mesafesinde $(25 \mathrm{~m}, 50 \mathrm{~m}, 75 \mathrm{~m})$ ayrıca kar üzerinde uygulanmıştır (Şekil 2). Çalışmada değerlendirilen parametrelerin normal dağ 1 lım özellikleri gösterebilmesi için minimum örnek büyüklüğü olan 30 sayıs1 dikkate alınmıştır (Batu, 1995). Bu amaçla her bir güzergahta 30 olmak üzere dört farklı güzergahta toplam 120 ölçüm yapılmıştır. Bölmeden çıkarma çalışmaları toplam üç işçi tarafindan gerçekleştirilmiştir. Değerlendirilen iş aşamaları; hazırlık aşaması, sürütme kancasının ürüne çekilmesi, sürütme kancasının ürüne bağlanması, ürünün sürütülmesi ve sürütme kancasının çıkarılmasıdır. 

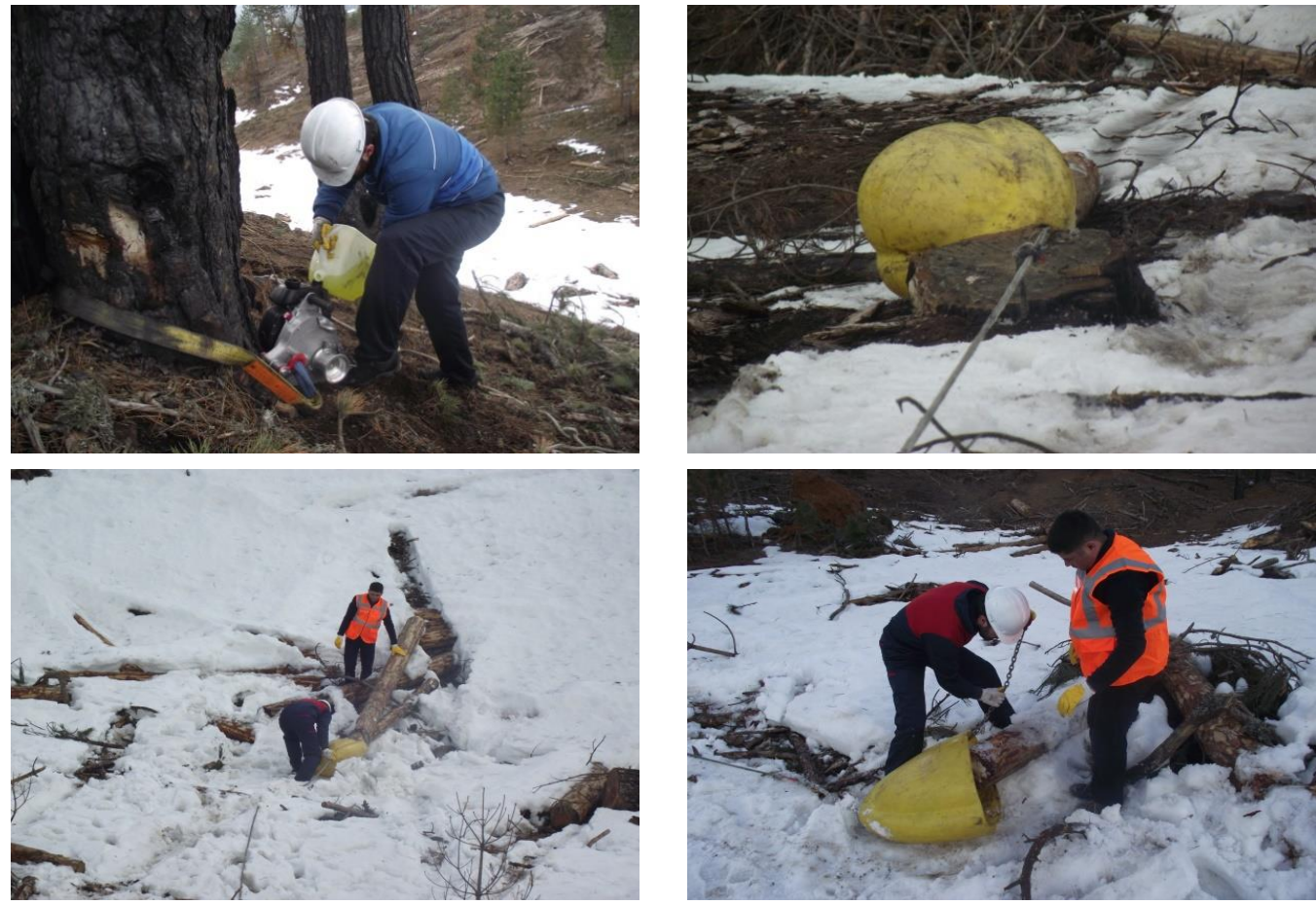

Şekil 2. Arazi çalışmaları

\section{Saatlik verim ölçümleri}

Bölmeden çıkarma çalışmalarının saatlik verimi zaman etüdü yöntemiyle belirlenmiştir. Zaman ölçümleri kronometre yardımıyla tekrarlı zaman ölçme tekniği kullanılarak gerçekleştirilmiştir.

Bölmeden çıkarma çalışmalarından elde edilen zaman değerlerinin kıaslanabilir duruma getirilmesi amacıyla, yapılan iş sırasında üretilen $1 \mathrm{~m}^{3}$ ürün için harcanan zaman dikkate alınarak değerlendirmeye uygun hale getirilmiştir.

Kesilmiş ağaçtan elde edilen ürünün hacmi belirlenirken, orta çap ve boya bağl1 olarak hesaplanan orta yüzey formülü kullanılmıştır (Carus, 2002):

$$
\begin{aligned}
& \mathrm{V}_{\mathrm{i}}=\frac{\pi}{40000} d_{\mathrm{i}}^{2} L_{\mathrm{i}} \\
& \mathrm{V}_{\mathrm{i}}=\mathrm{i} \text { ürününün hacmi }\left(\mathrm{m}^{3}\right) \\
& \mathrm{d}_{\mathrm{i}}=\mathrm{i} \text { ürününün orta çap1 }(\mathrm{cm}) \\
& \mathrm{L}_{\mathrm{i}}=\mathrm{i} \text { ürününün boyu }(\mathrm{m})
\end{aligned}
$$

Daha sonra hacim verisi verim formülünde yerine konularak üretim çalışmaları için saatlik verim hesaplanmıştır.

$$
\begin{aligned}
& \text { Verim }=\frac{\text { oŨH }}{\text { TS }} \times 60 \\
& \text { Verim }=\text { Saatlik verim }\left(\mathrm{m}^{3} / \mathrm{saat}\right) \\
& \text { OÜH }=\text { Bir döngüdeki ortalama ürün }
\end{aligned}
$$
hacmi
TS = Bir döngüdeki ortalama toplam süre (dk)

$60=$ Süreyi dakikadan saate çevirmek için kullanılan katsayı değeri

\section{İstatistiksel analizler}

İstatistiksel analizler kapsamında ölçümü yapılan ürünlerin hacimlerinin verim üzerine etkisini incelemek amaciyla her bir güzergahta değerlendirilen ürünler, hacimlerine bağlı olarak üç hacim sınıfına (düşük $<0,10 \mathrm{~m}^{3}$, orta: $0,10 \mathrm{~m}^{3}-0,15 \mathrm{~m}^{3}$, yüksek $>0,15 \mathrm{~m}^{3}$ ) ayrılmıştır. Ardından hacim sınıfı ve verim ilișkisi $\% 95$ güven düzeyinde Tek Yönlü Varyans Analizi (One-WayANOVA) ile incelenmiştir.

\section{Bulgular ve Tartışma}

Taşınabilir el vinciyle bölmeden çıkarma çalışmalarında her bir güzergaha ait ortalama değerler Tablo 1'de verilmiştir. Güzergah 1, 2,3 ve 4 'de sistemin kurulduğu alanda ortalama sürütme mesafesi ve ortalama arazi eğimi sırasıyla $25 \mathrm{~m}-\% 25,50 \mathrm{~m}-\% 25,50 \mathrm{~m}$ $\% 50$ ve $75 \mathrm{~m}-\% 50$ olarak tespit edilmiştir. Güzergah $1,2,3$ ve 4 için ortalama odun hammaddesi hacmi sirasiyla $0,12 \mathrm{~m}^{3}, 0,12$ $\mathrm{m}^{3}, 0,11 \mathrm{~m}^{3}, 0,11 \mathrm{~m}^{3}$ iken toplam çalışma zamanı ve verimleri sirasiyla $3,31 \mathrm{dk}-2,06$ $\left(\mathrm{m}^{3} / \mathrm{sa}\right), 4,68 \mathrm{dk}-1,46\left(\mathrm{~m}^{3} / \mathrm{sa}\right), 5,25 \mathrm{dk}-1,28$ 
$\left(\mathrm{m}^{3} / \mathrm{sa}\right), \quad 6,85 \mathrm{dk}-0,99 \quad\left(\mathrm{~m}^{3} / \mathrm{sa}\right)$ olarak hesaplanmıştır. Sonuçlara göre güzergah 1 ve güzergah 2'de arazi eğimleri aynı olsa da sürütme mesafesi güzergah 2'de daha fazla olduğu için toplam çalışma zamanı güzergah 2 'de daha yüksek çıkmıştır. Aynı durum güzergah 3 ve 4 için de söz konusu olmuştur.

Her bir güzergaha ait tek yönlü varyans (One-Way Anova) analizi sonuçları Tablo
2 'de verilmiştir. İstatistiksel analizler farklı hacim sınıflarının verim üzerine çok önemli $(p<0,01)$ etkisi olduğunu göstermiştir.

Taşınabilir el vinciyle sürütülen yüksek hacimli odun hammaddelerinin ortalama veriminin her dört güzergahta da, orta ve düşük hacim sınıfındakilere göre daha fazla olduğu tespit edilmiştir.

Tablo 1. Verim değişkenlerinin istatistiksel sonuçları

\begin{tabular}{cccccccc}
\hline Güzergahlar & $\begin{array}{c}\text { Sürütme } \\
\text { Mesafesi } \\
(\mathrm{m})\end{array}$ & $\begin{array}{c}\text { Arazi } \\
\text { Ĕgimi } \\
\%\end{array}$ & $\begin{array}{c}\text { Çap } \\
(\mathrm{cm})\end{array}$ & $\begin{array}{c}\text { Boy } \\
(\mathrm{m})\end{array}$ & $\begin{array}{c}\text { Hacim } \\
\left(\mathrm{m}^{3}\right)\end{array}$ & $\begin{array}{c}\text { Toplam } \\
\text { Çalışma } \\
\text { Zamanı } \\
(\mathrm{dk})\end{array}$ & $\begin{array}{c}\text { Verim } \\
\left(\mathrm{m}^{3} / \mathrm{saat}\right)\end{array}$ \\
\hline Güzergah 1 & 25 & 25 & 21,27 & 3,23 & 0,12 & 3,31 & 2,06 \\
Güzergah 2 & 50 & 25 & 21,63 & 3,13 & 0,12 & 4,68 & 1,46 \\
Güzergah 3 & 50 & 50 & 20,97 & 3,27 & 0,11 & 5,25 & 1,28 \\
Güzergah 4 & 75 & 50 & 21,03 & 3,23 & 0,11 & 6,85 & 0,99 \\
\hline
\end{tabular}

Tablo 2. Tek yönlü varyans (One-Way ANOVA) analizi sonuçları

\begin{tabular}{|c|c|c|c|c|c|c|c|c|}
\hline $\begin{array}{l}\text { Hacim } \\
\text { Sinıfları }\end{array}$ & $\begin{array}{c}\text { Toplam } \\
\text { Gözlem } \\
\text { Sayısı }\end{array}$ & Ortalama & $\begin{array}{c}\text { Std. } \\
\text { Sapma }\end{array}$ & $\begin{array}{l}\text { Std. } \\
\text { Hata }\end{array}$ & $\begin{array}{l}\text { 95\% Güve } \\
\text { Alt Sınır }\end{array}$ & Üst Sınır & Min. & Mak. \\
\hline \multicolumn{9}{|c|}{ Güzergah 1} \\
\hline Düşük & 11 & 1,4767 & 0,26763 & 0,08069 & 1,2966 & 1,6562 & 0,95 & 1,81 \\
\hline Orta & 12 & 2,2283 & 0,20639 & 0,05958 & 2,0972 & 2,3595 & 1,90 & 2,59 \\
\hline Yüksek & 7 & 2,7129 & 0,13438 & 0,05079 & 2,5886 & 2,8371 & 2,57 & 2,89 \\
\hline Toplam & 30 & 2,0657 & 0,53700 & 0,09804 & 1,8651 & 2,2662 & 0,95 & 2,89 \\
\hline \multicolumn{9}{|c|}{ Güzergah 2} \\
\hline Düşük & 12 & 1,0442 & 0,14254 & 0,04115 & 0,9536 & 1,1347 & 0,73 & 1,27 \\
\hline Orta & 12 & 1,5783 & 0,13354 & 0,03855 & 1,4935 & 1,6632 & 1,33 & 1,73 \\
\hline Yüksek & 6 & 2,0517 & 0,13877 & 0,05665 & 1,9060 & 2,1973 & 1,91 & 2,30 \\
\hline Toplam & 30 & 1,4593 & 0,40935 & 0,07474 & 1,3065 & 1,6122 & 0,73 & 2,30 \\
\hline \multicolumn{9}{|c|}{ Güzergah 3} \\
\hline Düşük & 13 & 0,9354 & 0,15290 & 0,04241 & 0,8430 & 1,0278 & 0,69 & 1,11 \\
\hline Orta & 11 & 1,4100 & 0,12345 & 0,03722 & 1,3271 & 1,4929 & 1,20 & 1,59 \\
\hline Yüksek & 6 & 1,8050 & 0,16694 & 0,06815 & 1,6298 & 1,9802 & 1,68 & 2,13 \\
\hline Toplam & 30 & 1,2833 & 0,36932 & 0,06743 & 1,1454 & 1,4212 & 0,69 & 2,13 \\
\hline \multicolumn{9}{|c|}{ Güzergah 4} \\
\hline Düşük & 12 & 0,6500 & 0,11362 & 0,03280 & 0,5778 & 0,7222 & 0,43 & 0,84 \\
\hline Orta & 11 & 1,1209 & 0,10005 & 0,03016 & 1,0537 & 1,1881 & 0,92 & 1,23 \\
\hline Yüksek & 7 & 1,3614 & 0,09045 & 0,03419 & 1,2778 & 1,4451 & 1,27 & 1,49 \\
\hline Toplam & 30 & 0,9887 & 0,31253 & 0,05706 & 0,8720 & 1,1054 & 0,43 & 1,49 \\
\hline
\end{tabular}

Sonuçlara göre el vinciyle bölmeden çıkarma çalışmalarının yüksek hacimli ürünlerde kullanılmasının daha verimli olacağı ortaya konmuştur (Şekil 3). Akay ve ark. (2014a) gerçekleştirdikleri benzer bir çalışmada verim değerinin, düşük hacim sınıfından, orta ve yüksek hacim sinıfina doğru artış gösterdiğini tespit etmişlerdir. 
Ortalama sürütme mesafeleri yaklaşık olarak ayn1 olan güzergah 3 ve 4 karşılaştırıldığında güzergah 4'ün eğimi fazla olduğu için ortalama verim değeri daha düşük çıkmıştır (Şekil 4). Gülci (2014) ve Akay ve ark. (2014a) tarafindan yapilan çalışmalarda da, taşınabilir el vincinin verimi ortalama eğim derecesi ile ters orantıl1 olduğu, yani ortalama eğim derecesi arttıkça verim değerinin azaldığ 1 ortaya konmuştur.

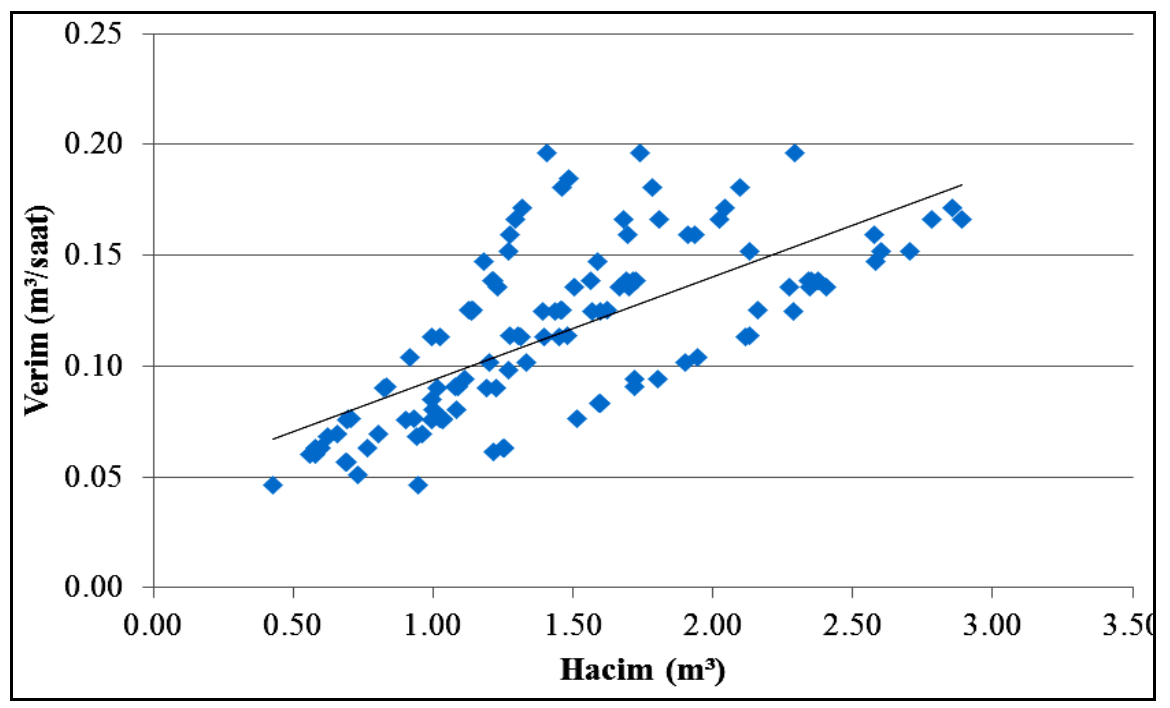

Şekil 3. Taşınabilir el vinci uygulamaları için verim-hacim ilişkisi

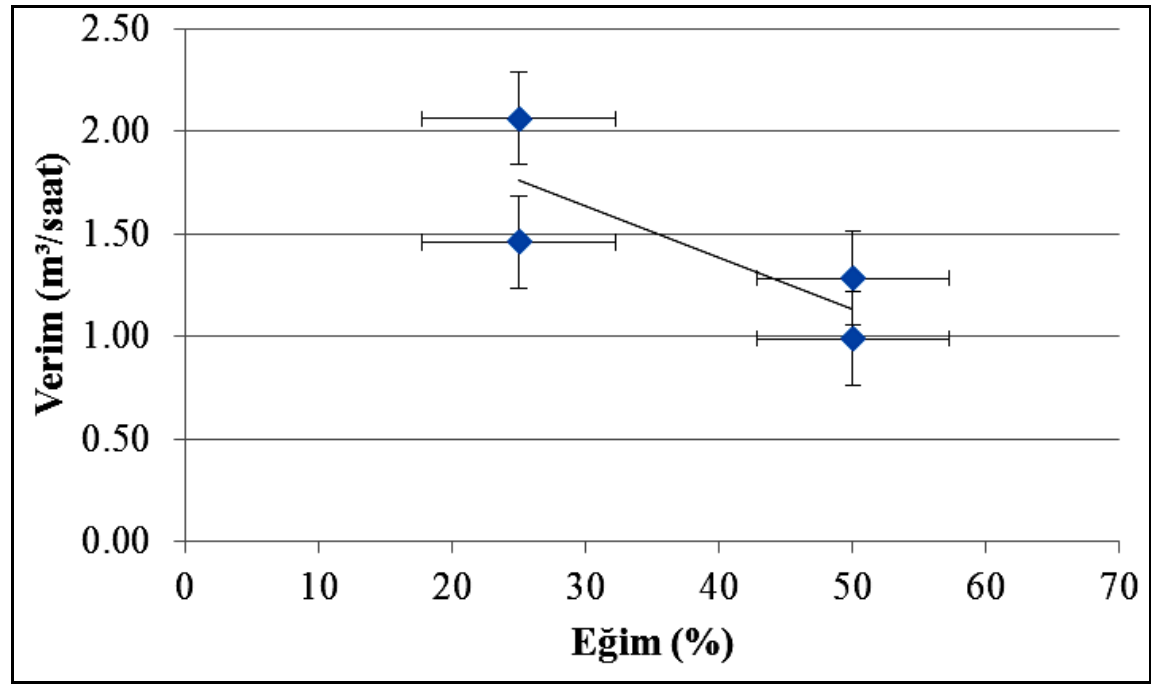

Şekil 4. Taşınabilir el vinci uygulamaları için verim-eğim ilişkisi

Taşınabilir el vinciyle bölmeden çıkarma çalışmalarının iş aşamalarının toplam zamana göre ortalama yüzde dağılımları Şekil 5'de görülmektedir. İş aşamalarının yüzdeleri karşılaştırıldığında, güzergahların tamamında sürütme kancasını çıkarma zamanı en az zaman alırken, güzergah 2, 3 ve 4'de sürütme zamanı en fazla zaman almıştır. Benzer bir çalışmada Gülci (2014)'de, toplam çalışma zamanı üzerinde en fazla zamanı alan iş aşamasının sürütme zamanı olduğunu ortaya koymuştur. Güzergah 1'de ise mesafenin diğer güzergahlara göre daha kısa olması nedeniyle hazırlık zamanı en fazla zaman alırken sürütme zamanı ikinci sırada fazla zaman almıştır. 


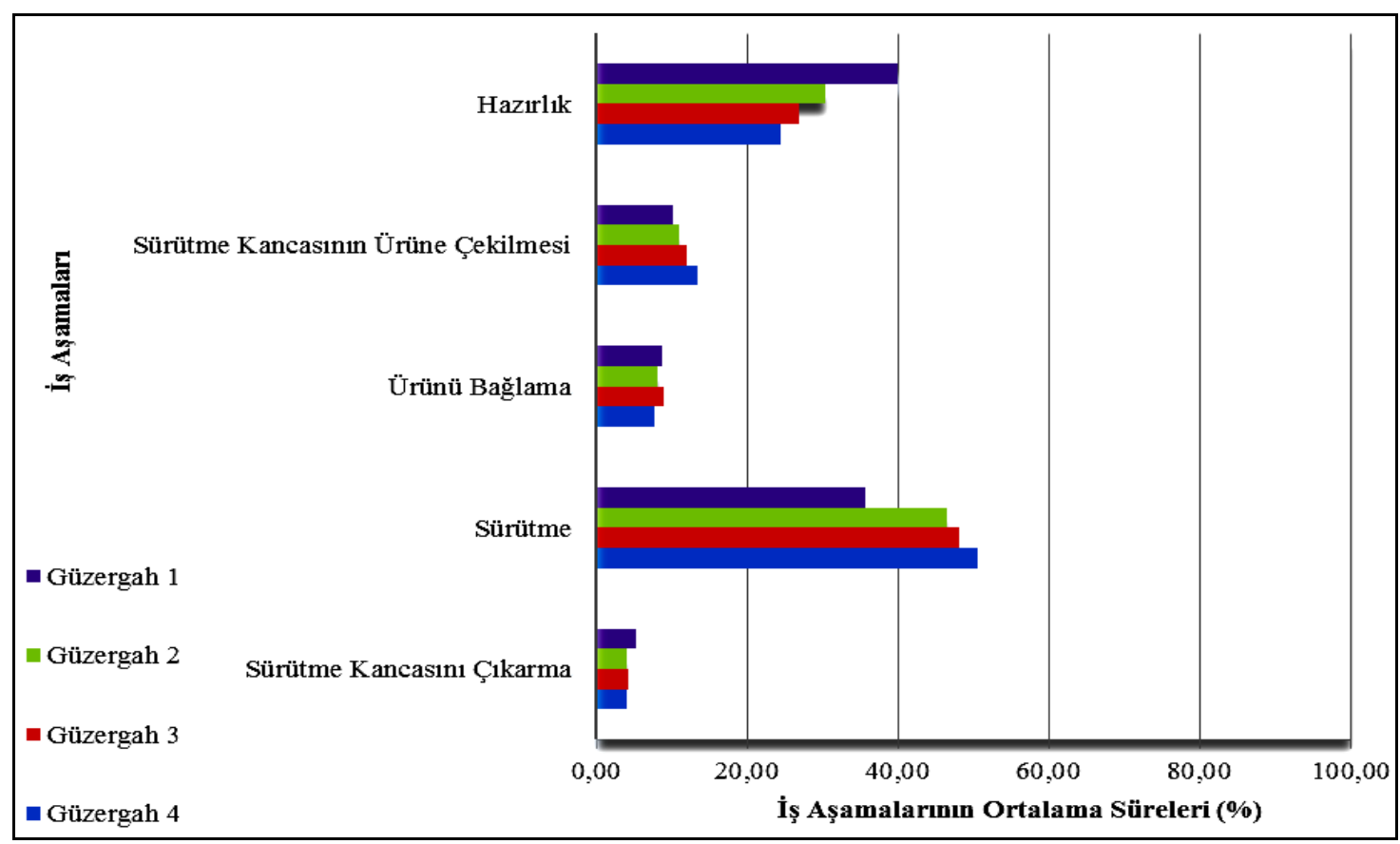

Şekil 5. Kar örtüsü üzerinde taşınabilir el vinci uygulamaları için iş dilimlerine göre ortalama yüzde değerleri

\section{Sonuçlar ve Öneriler}

Çalışmada, odun hammaddelerinin kar üzerinde ve sürütme konisi içerisinde taşınabilir el vinci kullanılarak sürütme çalışmaları verim açısından değerlendirilmiştir. Çalışma farklı arazi eğimi ve sürütme mesafesine sahip dört ayrı güzergahta gerçekleştirilmiştir.

Sonuçlara göre taşınabilir el vinciyle bölmeden çıkarma çalışmalarının düşük hacimli odun hammaddelerine kiyasla yüksek hacimli ürünlerde kullanılmasının daha verimli olduğu ortaya konmuştur. İş aşamalarının yüzdeleri karşılaştırıldığında, güzergahların tamamında sürütme kancasını çıkarma zamanı en az zamanı alırken, güzergah 2,3 ve 4 'de sürütme zaman1 en fazla zaman almıştır. Güzergah 1'de sürütme mesafesi diğerlerine kıyasla daha düşük olduğundan sürütme zamanı daha düşük çıkmıştır. Aynı zamanda sürütme mesafesinin artmasına bağlı olarak verimin azaldığı ortaya konmuştur.

Kış aylarında olumsuz hava şartları ve kar örtüsü nedeniyle bölmeden çıkarma çalışmalarında traktörler kullanılamamakta ve insan gücü kullanımı da kısitlı kalmaktadır. Bu nedenle özellikle zorlu kış şartlarında taşınabilir el vincinin bölmeden çıkarma çalışmalarında kullanılmasının iyi bir alternatif yöntem olacağ düşünülmektedir. El vincinin üretim işçinin omzunda yada sürütme konisi içerisinde çekilerek ergonomik bir şekilde taşınabilmesi bu yöntemin en önemli alternatifleri arasındadır. Ayrıca yol altında ve dere içinde kalmış odun hammaddelerinin yamaç yukarı çekilmesinde de kullanılabilmesi yöntemin büyük bir avantajı olarak düşünülmektedir.

\section{Kaynaklar}

Akay A.E., Sert M., Gülci N. 2014a. Hafif eğimli arazilerde benzinli el vinci ile bölmeden çıkarma çalışmalarının verim açısından değerlendirilmesi. II. Ulusal Orman ve Çevre Sempozyumu (22-24 Ekim 2014), Isparta.

Akay A.E., Sert M., Gülci N., Gülci S. 2014b. Küçük ölçekli ormancılık çalışmalarında ekolojik bir yaklaşım: benzinli el vinci. Ekoloji 2014 Sempozyumu (01-04 Mayıs 2014), GazimağusaKKTC, Kibris.

Batu F. 1995. Uygulamalı istatistik yöntemler. Karadeniz Teknik Üniversitesi, Orman Fakültesi, KTÜ Matbaası, Trabzon, Genel Yayın No: 179, Fakülte Yayın No: 22, 312 s.

Carus S. 2002. Bazı hacim formüllerinin seksiyon, gövde ve bağıl uzunluklara göre kıyaslanması. SDÜ Orman Fakültesi Dergisi, Seri A, Say1: 1, 101-114.

Erdaş O., Acar H.H., Eker M. 2014. Orman ürünleri transport teknikleri. Karadeniz Teknik Üniversitesi, Orman Fakültesi, KTÜ Matbaası, 
Trabzon, Genel Yayın No: 233, Fakülte Yayın No: 39, $504 \mathrm{~s}$.

Eroğlu H. 2012. Dağlık arazide farklı bölmeden çıkarma tekniklerinin orman toprağının sıkışmasına etkisi. Artvin Çoruh Üniversitesi Orman Fakültesi Dergisi, 13 (2), 213-225.

Gülci N. 2014. Üretim planlamasında hassas ormancılık üzerine araştırmalar. Doktora Tezi, KSÜ Fen Bilimleri Enstitüsü, 264 s. Kahramanmaraş.

Gülci N., Gülci S., Akay A.E., Erdaş O. 2014a. Odun hammaddesinin bölmeden çıkarılmasında alternatif bir yöntem: kollu el vinci. II. Ulusal Akdeniz Orman ve Çevre Sempozyumu (22-24 Ekim 2014), Isparta.

Gülci N., Akay A.E., Erdaş O. 2014b. Benzinli el vincinin odun hammaddesinin bölmeden çıkarılmasında kullanım imkanları. Orman Mühendisleri Odası, Orman Mühendisliği Dergisi, 51(1-3), 24-28.
Gülci N., Akay A.E., Erdaş O., Acar H. H., Michael W. 2016. Controlled sliding of logs downhill by chute system integrated with portable winch and synthetic rope. Journal of the Faculty of Forestry Istanbul University, 66 (1), 256-263.

Ünver S. 2008. Endüstriyel odun hammaddesinin insan gücüyle sürütülmesi sırasında ortaya çıkan ürün kayıpları ile çevresel zararların belirlenmesi üzerine bir araştırma. Doktora Tezi, KTÜ Fen Bilimleri Enstitüsü, 122 s. Trabzon.

Tunay M., Çı̆̆ F. 1994. Kastamonu yöresinde kar üzerinde üretim çalışmaları. İstanbul Üniversitesi Orman Fakültesi Dergisi, Seri B, 44 (1-2), 155-166. 